\title{
Association Between Exposure to Environmental Tobacco Smoke at the Workplace and Risk for Developing a Colorectal Adenoma: A Cross-Sectional Study
}

\author{
Seung-Hwa Lee, Ji-Yeon Hong ${ }^{1}$, Jung-Un Lee ${ }^{1}$, Dong Ryul Lee ${ }^{1}$ \\ Health Promotion Center, Seohae Hospital, Seocheon; ${ }^{1}$ Health Promotion Center, Wonkwang University Sanbon Hospital, Wonkwang \\ University College of Medicine, Gunpo, Korea
}

Purpose: A colorectal adenoma (CRA) is a well-defined precursor to colorectal cancer (CRC). Additionally, smoking is a potent risk factor for developing a CRA, as well as CRC. However, the association between exposure to environmental tobacco smoke (ETS) and the risk for developing a CRA has not yet been fully evaluated in epidemiologic studies. We performed a cross-sectional analysis on the association between exposure to ETS at the workplace and the risk for developing a CRA.

Methods: The study was conducted on subjects who had undergone a colonoscopy at a health promotion center from January 2012 to December 2012. After descriptive analyses, overall and subgroup analyses by smoking status were performed by using a multivariate logistic regression.

Results: Among the 1,129 participants, 300 (26.6\%) were diagnosed as having CRAs. Exposure to ETS was found to be associated with CRAs in all subjects (fully adjusted odds ratio [OR], 1.95; 95\% confidence interval [CI], 1.08-2.44; $\mathrm{P}=0.001$ ). In the subgroup analysis, exposure to ETS in former smokers increased the risk for developing a CRA (fully adjusted OR, 4.44; 95\% CI, 2.07-9.51; P < 0.001).

Conclusion: Exposure to occupational ETS at the workplace, independent of the other factors, was associated with increased risk for developing a CRA in all subjects and in former smokers. Further retrospective studies with large sample sizes may be necessary to clarify the causal effect of this relationship.

Keywords: Environmental tobacco smoke; Passive smoke; Secondhand smoke; Colorectal adenoma

\section{INTRODUCTION}

Colorectal neoplasms have become a worldwide concern [1]. Colorectal cancer (CRC) is one of the most common malignancies in the developed world, such as North America [2] and Europe [3], and the incidence of CRC appears to be increasing in East Asian countries, including Korea [4, 5]. Colorectal polyps,

Received: April 19, 2015 - Accepted: March 14, 2016

Correspondence to: Dong Ryul Lee, M.D.

Health Promotion Center, Wonkwang University Sanbon Hospital, Wonkwang University College of Medicine, 327 Sanbon-ro, Gunpo 15865, Korea

Tel: +82-31-390-2300, Fax: +82-31-219-5561

E-mail: rednose1@hanmail.net

(C) 2016 The Korean Society of Coloproctology

This is an open-access article distributed under the terms of the Creative Commons Attribution NonCommercial License (http://creativecommons.org/licenses/by-nc/4.0) which permits unrestricted noncommercial use, distribution, and reproduction in any medium, provided the original work is properly cited. especially the adenomatous type, are reputed to be precancerous lesions that might develop into $\mathrm{CRC}$, i.e., an adenoma-carcinoma sequence [6-8]. Furthermore, the removal and/or prevention of these lesions was shown to be able to reduce the incidence of CRC $[9,10]$.

Tobacco smoke contains approximately 4,000 toxic chemicals, including oxidative gases, heavy metals, cyanide, and at least 50 carcinogens [11]. Environmental tobacco smoke (ETS), i.e., secondhand smoke or passive smoking, is defined as tobacco smoke produced by an active smoker both from the exhalation of smoked tobacco and from the burning end of the cigarette that is inhaled by the other person [12]. Active smoking is one of the risk factors for developing CRC. Previous studies have shown that it is associated with colorectal adenomas (CRAs), which are premalignant lesions of CRC [13-18]. However, few studies regarding exposure to ETS (passive smoking) and the risk for developing CRC have been performed $[19,20]$. Furthermore, to the best of our 
knowledge through an extensive literature review, no study has investigated the effect of exposure to ETS on the risk for developing a CRA. Therefore, the aim of the study was to evaluate the relationship between exposure to ETS in the workplace and the risk for developing a CRA.

\section{METHODS}

\section{Study population}

One thousand five hundred eighty-six $(1,586)$ Koreans older than 20 years of age who had a first-time diagnosis of a CRA during colonoscopy at the Health Promotion Center, Wonkwang University Hospital, Gunpo, South Korea, from January 2012 to December 2012 were eligible for this study, and their case files and were reviewed for inclusion in this study. Among the initial 1,586 subjects, 457 were excluded for the following reasons: (1) missing data on the medical records; (2) incomplete colonoscopic examination due to inadequate bowel cleansing; (3) previous history of malignancy or inflammatory bowel disease; (4) underlying diseases such as diabetes mellitus, cardiovascular and cerebrovascular disease, chronic renal failure, and hepatobiliary diseases; (5) presence of an obstructive lesion, such as CRC, in the large intestine; (6) family history of CRC in first-degree relatives; and (7) use of medications such as nonsteroidal anti-inflammatory drugs (NSAIDs), aspirin, exogenous hormone replacement therapy (HRT) in women, and vitamin D. As a result, a total of 1,129 subjects were included for the final analyses. A flow diagram of the analyses is shown in Fig. 1. This study was approved by the Institutional Review Board, Wonkwang University College of Medi-

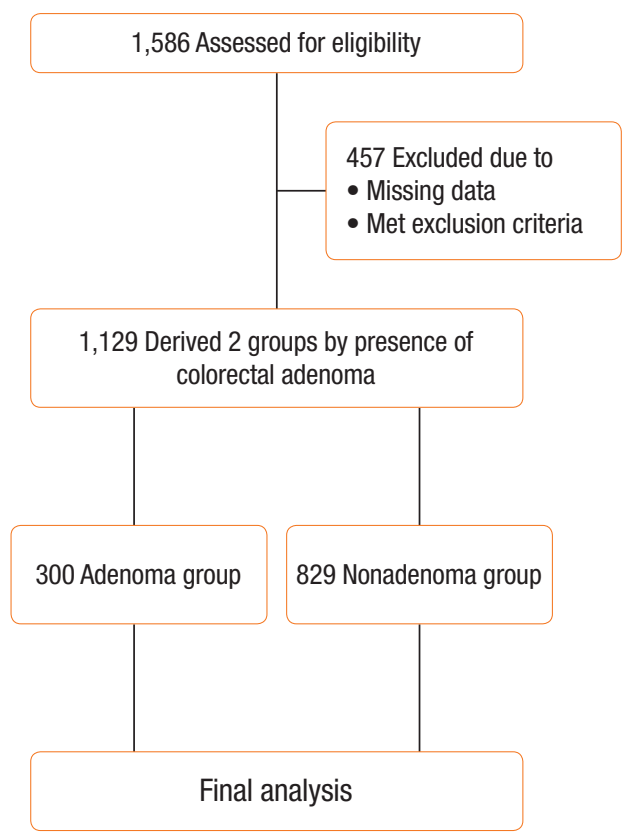

Fig. 1. Flow chart of the study design. cine, Gunpo, South Korea (7302-201422).

\section{Data collection}

The heights and body weights of participants were measured while they were wearing light clothing without shoes. The body mass index (BMI) was calculated as the weight divided by height squared $\left(\mathrm{kg} / \mathrm{m}^{2}\right)$. Data on alcohol consumption, exercise, and cigarette smoking on all included subjects were collected by using a self-administered questionnaire. The alcohol consumption of the subjects was calculated and then converted to weekly alcohol consumption ( $\mathrm{g} / \mathrm{wk}$, grams of ethanol per week) by using the graduated frequency method [21]. Exercise was also calculated and then converted to the metabolic equivalent of task hours per week [22]. Smoking status was divided into three categories (never a smoker vs. former smoker vs. current smoker). The detailed information regarding cigarette smoking habits was collected as follows: (1) cumulative smoking amount ( $<10$ pack-year, 10 to $<20$ pack-year, $\geq 20$ pack-year); (2) cigarettes smoked per day $(<1$ pack, $\geq 1$ pack); (3) duration of smoking ( $<20$ years, $\geq 20$ years); (4) duration since smoking cessation in ex-smoker ( $<10$ years, 10 to $<20$ years, $\geq 20$ years); (5) time of daily exposure to ETS in the workplace (never exposed, $<1$ hour, $\geq 1$ hour) [23]. Overnightfasting blood samples were drawn from the antecubital area. White blood cell (WBC) count, aspartate aminotransferase (AST), alanine aminotransferase (ALT), gamma-glutamyl transferase $(\gamma$ GT), total cholesterol, triglycerides (TGs), high-density lipoprotein cholesterol (HDL-C), low-density lipoprotein cholesterol, and glycated hemoglobin (HbAlc) were measured by using automatic analyzers: K-4500 (TOA Medical Electronics, Kobe, Japan) for WBC count; TBA-200FR (Toshiba Medical Systems Co. Ltd., Tokyo, Japan) for AST, ALT, $\gamma$-GT, and lipid panel; ADAMS HA8180 (Arkray Inc., Tokyo, Japan) for HbAlc.

All colorectal polyps detected during colonoscopy were confirmed by using a histopathological evaluation of the retrieved lesions. Subjects with an adenomatous polyp were classified according to (1) number (single vs. multiple); (2) size [small $(<1 \mathrm{~cm})$ vs. large $(\geq 1 \mathrm{~cm})$ ]; (3) anatomical location (right-sided, left-sided, both-sided); (4) histologic type (tubular, tubulovillous, villous). Right-sided colon was defined as the cecum, and the ascending and transverse colon; left-sided colon was defined as the descending and sigmoid colon, and the rectum. Cases with both right and left CRAs were assigned as both-sided.

\section{Statistical analysis}

All continuous variables are expressed as means \pm standard deviations whereas categorical variables are presented as numbers and percentages. The characteristics of the study subjects were compared by using the independent $\mathrm{t}$-test for continuous variables and the chi-square tests for categorical variables, as appropriate. We conducted multivariable logistic regression analyses to examine whether exposure to ETS in the workplace was significantly associated with the occurrence of a CRA. The odds ratios (ORs) 
with 95\% confidential intervals (CIs) were estimated for ETS exposures less than 1 hour and for ETS exposures greater than or equal to 1 hour, with the category of never having been exposed to ETS as the reference. For controlling confounders, adjusted models were applied: model 1 (age/sex) and model 2 (model 1 plus BMI/alcohol consumption/physical activity/total smoking amount/HbA1c/TG/HDL). We also performed subgroup analyses according to smoking status. Tests for linear trends ( $\mathrm{P}$ for trend) were conducted by entering the categorical variable (ETS exposure time) into the regression models as an ordinal term. All statistical analyses were performed using SPSS ver. 17.0 (SPSS Inc., Chicago, IL, USA). A P-value less than 0.05 was considered statistically significant.

\section{RESULTS}

\section{Baseline and adenoma characteristics of study subjects}

Histopathologic analyses of the 1,129 subjects included 300 subjects in the adenoma group and 829 in the nonadenoma group. The baseline characteristics of all subjects and both groups are summarized in Table 1 . The subjects in the adenoma group were older $(\mathrm{P}<0.001)$, male-dominant $(\mathrm{P}<0.001)$, and relatively overweight $(\mathrm{P}=0.005)$ compared to those in the nonadenoma group. Additionally, the subjects in the adenoma group consumed more alcohol $(\mathrm{P}<0.001)$. However, no significant differences in exercise were noted between the 2 groups. With regard to laboratory tests, serum levels of $\gamma$-GT, TG, and HbAlc $(\mathrm{P}<0.001, \mathrm{P}<0.001$, and $\mathrm{P}=0.002$, respectively) were higher and HDL-C $(\mathrm{P}=0.001)$ was lower in the adenoma group. However, the other variables on laboratory tests were not significantly different between the two groups. The study subjects who had a CRA showed the following characteristics: number (single vs. multiple: $60.0 \%$ vs. $40.0 \%$ ); size (small vs. large: $85.0 \%$ vs. $15.0 \%$ ); anatomical site (right-sided vs. left-sided vs. both-sided: $39.3 \%$ vs. $41.7 \%$ vs. $19.0 \%$ ); histologic type (tubular vs. tubulovillous vs. villous: $92.0 \%$ vs. $7.0 \%$ vs. $1.0 \%$ ) (Table 2).

\section{Smoking-related characteristics between the 2 groups}

Of the total 1,129 subjects 472 (41.8\%) had never smoker, 368 (32.6\%) were former smokers, and 289 (25.6\%) were current smoker. Total smoking amount, cigarettes smoked per day, and smoking duration in current smokers and former smokers were $10.1 \pm 12.6$ pack-year, $0.48 \pm 0.50$ cigarettes/day, and $20.0 \pm 9.1$ years, respectively. The subjects not exposed to ETS in the workplace were $580(51.4 \%)$ and those exposed to ETS were 549 (48.6\%). The subjects exposed to ETS in the workplace were subdivided into 2 categories: those exposed $<1$ hour (399 of 549, $72.7 \%$ ) and those exposed $\geq 1$ hour (150 of 549, 27.3\%).

Table 3 shows a comparison of the smoking characteristics between the 2 groups (nonadenoma group vs. adenoma group). When compared to the subjects with CRAs, the nonadenoma group had a lower amount of cumulative smoking (16.0 \pm 10.8
Table 1. Baseline characteristics between the two groups (nonadenoma group vs. adenoma group)

\begin{tabular}{|c|c|c|c|c|}
\hline Characteristic & $\begin{array}{l}\text { All subject } \\
(n=1,129)\end{array}$ & $\begin{array}{c}\text { Nonadenoma } \\
\text { group } \\
(\mathrm{n}=829)\end{array}$ & $\begin{array}{l}\text { Adenoma } \\
\text { group } \\
(n=300)\end{array}$ & P-value \\
\hline Age (yr) & $44.8 \pm 9.3$ & $43.8 \pm 9.1$ & $47.5 \pm 9.2$ & $<0.001$ \\
\hline Age group (yr) & & & & $<0.001$ \\
\hline$\leq 40$ & $380(33.7)$ & $314(37.9)$ & $66(22.0)$ & \\
\hline $41-50$ & 467 (41.4) & 327 (39.4) & $140(46.7)$ & \\
\hline $51-60$ & 217 (19.2) & 151 (18.2) & $66(22.0)$ & \\
\hline$\geq 61$ & $65(5.8)$ & $37(4.5)$ & $28(9.3)$ & \\
\hline Sex & & & & $<0.001$ \\
\hline Male & 801 (70.9) & 555 (66.9) & $246(82.0)$ & \\
\hline Female & $328(29.1)$ & $274(33.1)$ & $54(18.0)$ & \\
\hline BMI $\left(\mathrm{kg} / \mathrm{m}^{2}\right)$ & $24.1 \pm 3.1$ & $24.0 \pm 3.2$ & $24.6 \pm 3.1$ & 0.005 \\
\hline BMl group $\left(\mathrm{kg} / \mathrm{m}^{2}\right)$ & & & & 0.169 \\
\hline$<23$ & 421 (37.3) & $323(39.0)$ & $98(32.7)$ & \\
\hline $23-25$ & 287 (25.4) & $206(24.8)$ & $81(27.0)$ & \\
\hline$>25$ & 421 (37.3) & $300(36.2)$ & $121(40.3)$ & \\
\hline $\begin{array}{l}\text { Waist } \\
\text { circumference } \\
\text { (cm) }\end{array}$ & $81.1 \pm 9.3$ & $80.4 \pm 9.4$ & $82.9 \pm 8.9$ & $<0.001$ \\
\hline Alcohol (g/wk) & $111.2 \pm 155.4$ & $99.9 \pm 137.6$ & $142.7 \pm 193.1$ & $<0.001$ \\
\hline $\begin{array}{l}\text { Exercise } \\
\text { (MET hr/wk) }\end{array}$ & $29.7 \pm 57.2$ & $29.0 \pm 55.5$ & $31.6 \pm 61.7$ & 0.503 \\
\hline WBC $\left(\times 10^{3} / \mu \mathrm{L}\right)$ & $5.9 \pm 1.6$ & $5.9 \pm 1.6$ & $6.0 \pm 1.7$ & 0.126 \\
\hline AST (IU/L) & $28.8 \pm 19.5$ & $28.1 \pm 19.4$ & $30.6 \pm 19.8$ & 0.054 \\
\hline ALT (IU/L) & $29.5 \pm 29.1$ & $28.6 \pm 30.4$ & $31.8 \pm 25.0$ & 0.109 \\
\hline$\gamma$-GT (IU/L) & $44.4 \pm 52.8$ & $39.9 \pm 40.1$ & $56.7 \pm 76.4$ & $<0.001$ \\
\hline $\mathrm{TC}(\mathrm{mg} / \mathrm{dL})$ & $197.8 \pm 32.7$ & $196.9 \pm 32.4$ & $200.2 \pm 33.6$ & 0.135 \\
\hline TG (mg/dL) & $123.3 \pm 99.4$ & $115.5 \pm 89.7$ & $144.9 \pm 119.7$ & $<0.001$ \\
\hline HDL-C (mg/dL) & $53.4 \pm 13.7$ & $54.2 \pm 13.8$ & $51.2 \pm 13.2$ & 0.001 \\
\hline LDL-C (mg/dL) & $123.7 \pm 30.5$ & $122.8 \pm 30.0$ & $126.1 \pm 31.8$ & 0.113 \\
\hline $\mathrm{HbA}_{1 \mathrm{c}}(\%)$ & $5.7 \pm 0.7$ & $5.6 \pm 0.6$ & $5.8 \pm 0.9$ & 0.002 \\
\hline
\end{tabular}

Values are presented as mean \pm standard deviation or number (\%).

BMI, body mass index; MET, metabolic equivalent of task; WBC, white blood cell; AST, aspartate aminotransferase; ALT, alanine aminotransferase; $\gamma$-GT, gammaglutamyl transferase; TC, total cholesterol; TG, triglyceride; HDL-C, high-density lipoprotein cholesterol; LDL-C, low-density lipoprotein cholesterol; $\mathrm{HbA}_{1 c}$, glycated hemoglobin.

${ }^{\text {aP }}$-values were calculated by using the independent t-test for continuous variables and Pearson chi-square test for categorical variables.

pack-year vs. $20.5 \pm 13.9$ pack-year, $\mathrm{P}<0.001$ ), a higher proportion of those who had never smoked ( $45.1 \%$ vs. $32.7 \%, \mathrm{P}=0.001$ ), and shorter durations of smoking (18.8 \pm 8.8 years vs. $22.8 \pm 9.3$ years, $\mathrm{P}<0.001)$ and exposure to ETS $(46.9 \%$ vs. $53.5 \%, \mathrm{P}=0.002)$. However, no significant differences in cigarettes smoked per day 


\section{Coloproctology semo-ina lece cal}

Table 2. Clinicopathologic characteristics of colorectal adenomas in the adenoma group

\begin{tabular}{lc}
\hline Variable & Adenoma group $(\mathrm{n}=300)$ \\
\hline No. of CRA & \\
Single & $180(60.0)$ \\
Multiple & $120(40.0)$ \\
Size of CRA & \\
Small & $255(85.0)$ \\
Large & $45(15.0)$ \\
Anatomical site of CRA ${ }^{\mathrm{c}}$ & \\
Right-sided & $125(39.3)$ \\
$\quad$ Left-sided & $118(41.7)$ \\
Both-sided & $57(19.0)$ \\
Histologic type of CRA & \\
Tubular & $276(92.0)$ \\
Tubulovillous & $21(7.0)$ \\
Villous & $3(1.0)$ \\
\hline
\end{tabular}

Values are presented as number (\%).

CRA, colorectal adenoma.

aSingle (one CRA) vs. multiple (more than one CRA). ${ }^{\text {'S }}$ mall $(<1 \mathrm{~cm})$ vs. large $(\geq 1$ $\mathrm{cm}$ ). 'Right-sided (cecum, ascending, and transverse colon) vs. left-sided (descending and sigmoid colon, and rectum) vs. both-sided (both right-sided and leftsided CRAs). "Histologic types of all CRAs were confirmed by using histopathologic evaluations and were classified as tubular vs. tubulovillous vs. villous.

(former and current smokers, $\mathrm{P}=0.196$ ) and in duration since quitting smoking (former smoker, $\mathrm{P}=0.781$ ) were noted.

Relationship between ETS exposure and CRA in the subjects Table 4 presents the relationship between exposure to ETS in the workplace and the risk of developing a CRA overall and by subset (smoking status). Exposure to ETS in the workplace for longer than 1 hour was associated with a higher risk of developing a CRA (OR, 1.95; 95\% CI, 1.33-2.85; $\mathrm{P}=0.001$ ). The association remained statistically significant even after the data had been fully adjusted (OR, 1.62; 95\% CI, 1.08-2.44; $\mathrm{P}=0.021)$. The risk of developing an adenoma was significantly correlated with increased duration of exposure to ETS ( $\mathrm{P}$ for trend $=0.002$ for the unadjusted model, 0.011 for model 1 , and 0.046 for model 2 ). We performed subgroup analyses to evaluate whether the risk for developing a CRA associated with the duration of exposure to ETS varied by smoking status. Among former smokers, the risk for developing a CRA was significantly correlated with increased duration of exposure to ETS ( $\mathrm{P}$ for trend $=0.001$ for the unadjusted model, $<0.001$ for model 1 , and $<0.001$ for model 2). After the data had been fully adjusted (model 2), the former smokers with daily exposures to ETS of longer than 1 hour had significantly higher risks for developing a CRA than those who had never been exposed to ETS (OR, 4.44; 95\% CI, 2.07-9.51; P < 0.001). However, this difference was not observed between subjects who had
Table 3. Comparison of smoking characteristics between the 2 groups

\begin{tabular}{|c|c|c|c|}
\hline Variable & $\begin{array}{c}\text { Nonadenoma } \\
\text { group } \\
(\mathrm{n}=829)\end{array}$ & $\begin{array}{l}\text { Adenoma } \\
\text { group } \\
(n=300)\end{array}$ & P-value ${ }^{a}$ \\
\hline Smoking status ${ }^{b}$ & & & $<0.001$ \\
\hline Never smoker & $374(45.1)$ & $98(32.7)$ & \\
\hline Former smoker & $262(31.6)$ & $106(35.3)$ & \\
\hline Current smoker & $193(23.3)$ & $96(32.0)$ & \\
\hline Total smoking amount (pack-yr) ${ }^{c}$ & $16.0 \pm 10.8$ & $20.5 \pm 13.9$ & $<0.001$ \\
\hline $\begin{array}{l}\text { Grading of total smoking } \\
\text { amount (pack-yr) }\end{array}$ & & & 0.004 \\
\hline$<10$ & $155(34.0)$ & $57(28.4)$ & \\
\hline $10,<20$ & $172(37.7)$ & $61(30.3)$ & \\
\hline$\geq 20$ & $129(28.3)$ & $83(41.3)$ & \\
\hline Cigarettes (packs) per day smoked ${ }^{c}$ & $0.82 \pm 0.39$ & $0.85 \pm 0.38$ & 0.331 \\
\hline $\begin{array}{l}\text { Grading of cigarettes per day } \\
\text { smoked }(\text { pack) }\end{array}$ & & & 0.205 \\
\hline$<1$ & $425(93.4)$ & $183(90.5)$ & \\
\hline$\geq 1$ & $30(6.6)$ & $19(9.5)$ & \\
\hline Duration of smoking $(\mathrm{yr})^{\mathrm{c}}$ & $18.8 \pm 8.8$ & $22.8 \pm 9.2$ & $<0.001$ \\
\hline Grading of smoking duration $(y r)^{c}$ & & & $<0.001$ \\
\hline$<20$ & $289(63.5)$ & $94(46.5)$ & \\
\hline$\geq 20$ & $166(36.5)$ & $108(53.5)$ & \\
\hline Duration since quitting smoking $(y r)^{d}$ & & & 0.781 \\
\hline$<10$ & $148(56.5)$ & $64(60.4)$ & \\
\hline $10,<20$ & $83(31.7)$ & $30(28.3)$ & \\
\hline$\geq 20$ & $31(11.8)$ & $12(11.3)$ & \\
\hline Time of ETS exposure at work $(\mathrm{hr})^{\mathrm{b}}$ & & & 0.003 \\
\hline Never exposed & $440(53.1)$ & $140(46.7)$ & \\
\hline$<1$ & $296(35.7)$ & $103(34.3)$ & \\
\hline$\geq 1$ & $93(11.2)$ & $57(19.0)$ & \\
\hline
\end{tabular}

Values are presented as number (\%) or mean \pm standard deviation.

ETS, environmental tobacco smoke.

ap-values were calculated by using the independent t-test for continuous variables and Pearson chi-square test for categorical variables. ${ }^{b}$ Never plus former plus current smoker. ${ }^{~}$ Former plus current smoker. ${ }^{~}$ Former smoker.

never smoked and those who were current smokers.

\section{DISCUSSION}

This study was designed to investigate the association between exposure to occupational ETS and the risk for developing a CRA. In order to minimize their influence on the analyses done in this study, we used specific criteria to exclude subjects with known or suspected risk factors affecting the incidence of and the detection rate for a CRA, including family history, underlying disease, use of a few medications, and quality of bowel preparation for colo- 
Table 4. Risk of colorectal adenomas according to smoking status and daily time of exposure to occupational environmental tobacco smoke

\begin{tabular}{|c|c|c|c|}
\hline \multirow{2}{*}{ Variable } & \multicolumn{3}{|c|}{ ETS exposure time at workplace (hr/day) } \\
\hline & Unadjusted & Model 1 & Model 2 \\
\hline \multicolumn{4}{|c|}{ All subjects } \\
\hline 0 & 1.00 (Reference) & 1.00 (Reference) & 1.00 (Reference) \\
\hline$<1$ & $1.10(0.82-1.48)$ & $1.05(0.77-1.44)$ & $1.04(0.76-1.43)$ \\
\hline$\geq 1$ & $1.95(1.33-2.85)$ & $1.81(1.22-2.70)$ & $1.62(1.08-2.44)$ \\
\hline \multicolumn{4}{|c|}{ Never smoker } \\
\hline 0 & 1.00 (Reference) & 1.00 (Reference) & 1.00 (Reference) \\
\hline$<1$ & $0.92(0.55-1.51)$ & $0.87(0.50-1.51)$ & $0.83(0.47-1.46)$ \\
\hline$\geq 1$ & $0.60(0.20-1.80)$ & $0.55(0.18-1.69)$ & $0.52(0.17-1.60)$ \\
\hline \multicolumn{4}{|c|}{ Former smoker } \\
\hline 0 & 1.00 (Reference) & 1.00 (Reference) & 1.00 (Reference) \\
\hline$<1$ & $1.31(0.80-2.16)$ & $1.42(0.84-2.38)$ & $1.45(0.86-2.44)$ \\
\hline$\geq 1$ & $4.11(1.99-8.49)$ & $4.54(2.14-9.63)$ & $4.44(2.07-9.51)$ \\
\hline \multicolumn{4}{|c|}{ Current smoker } \\
\hline 0 & 1.00 (Reference) & 1.00 (Reference) & 1.00 (Reference) \\
\hline$<1$ & $0.91(0.50-1.64)$ & $1.04(0.56-1.94)$ & $1.00(0.52-1.92)$ \\
\hline$\geq 1$ & $1.30(0.72-2.36)$ & $1.42(0.76-2.65)$ & $1.18(0.61-2.29)$ \\
\hline
\end{tabular}

Values are presented as odds ratio (95\% confidence interval).

Odd ratios with $95 \%$ confidential intervals were calculated by using a multivariable logistic regression analysis.

Model 1, adjusted for age and sex; model 2, adjusted for model 1 plus body mass index, exercise, alcohol, pack/yr smoked, glycated hemoglobin, triglyceride, and high-density lipoprotein cholesterol; ETS, environmental tobacco smoke.

noscopy. Our study showed that the risk for developing a CRA was associated with exposure to ETS in the workplace. Our results also indicated that the duration of exposure to ETS had a significant, positive relationship with the risk for developing a CRA, especially for former smokers.

Exposure to ETS, also known as secondhand or passive smoke, is an involuntary exposure of subjects to tobacco smoke [24, 25]. ETS significantly contributes to morbidity and mortality in children and adults. In 1993, the American EPA (environmental protection agency) report classified ETS as a Group A carcinogen, a designation for sufficient evidence that the substance causes cancer in humans [26]. A CRA is known to be precursor lesion for CRC; it can develop into CRC mostly through an adenoma-carcinoma sequence. The results of the present study correspond with the results of earlier studies that reported a significant positive correlation between exposure to occupational ETS and the risk for developing CRC [20, 27, 28]. Previously, Gerhardsson de Verdier et al. [27] reported that occupational exposure to passive smoke was associated with significantly increased risk for developing colon cancer. Slattery et al. [28], in a case-control study, also demonstrated that exposure to ETS increased the risk for devel- oping CRC even after the data had been adjusted for confounding factors, although the investigators focused only on the rectum. Some studies, in contrast, showed that ETS exposure at home and in the workplace had no effect on the risk for developing invasive colorectal neoplasms $[14,19]$. The discrepancies in these findings may have stemmed from the limitations of the studies such as inadequate adjustment for confounding variables (e.g., adjustments for only age and for the residual effect of active smoking by including those who had always smoked), lack of consideration for the recency of ETS exposure, and classification of the exposure as a simple dichotomous variable (never vs. chronically exposed) without considering the duration of exposure. However, some inconclusive evidence has suggested that exposure to ETS might influence the risk of for developing a CRA or CRC $[14,19,20$, 2729]. This observation was also in line with studies on the effects of active smoking on the risk for developing a CRA. However, caution is required in extrapolating the results for the association between active smoking and the risk for developing a CRA or between exposure to ETS and the risk for developing CRC. Hence, further large-scale studies directly focusing on the relationship between exposure to ETS and the CRA risk are necessary to clarify our study results.

We also investigated the effect of exposure to ETS among current and former smokers, as well as those who had never smoked, and found that the relationship between exposure to ETS and the risk for developing a CRA was observed only in former smoker, not in those who had never smoked and and not in current smokers. The effect of exposure to ETS was present under the residual effect of previous smoking, but not under the residual effect of having never smoked. This phenomenon was inconsistent with the findings of other studies that evaluated the relationship between passive smoking and the risk for developing cancer of the pancreas [30] and the respiratory tract [31]. Moreover, our results showed that the dose-response relationship between exposure to ETS and the risk for developing a CRA was not present in current smokers. This is plausible in that the effect of exposure to ETS may be minimized by the overwhelming effect of current activesmoking.

Our data indicate the effect of exposure to ETS in the workplace on the risk for developing colorectal adenomatous polyps. Exposure to ETS is a serious public health issue because it has diverse adverse health effects, including malignancy (lung, pancreas, breast) [30-33], cardiovascular disease [34], osteoporosis [23], and exacerbation of asthma [35]. Exposure to ETS at work is increasingly becoming a more important public health issue than exposure to ETS at home because exposure to ETS in the workplace can be restricted by legislation. In reality, many investigators have already reported a decline in the incidence of ETS-related diseases upon implementation of legislation requiring public places to be smoke free [36]. The findings of the present study indicate yet another detrimental effect of exposure to ETS in the workplace, which could serve as additional scientific support for smoke-free 
legislation and policies.

The results of our investigation were supported by various mechanisms for the relationship between cigarette smoking, developing a CRA and developing CRC. Firstly, cigarette smoking leads to CRCs through genetic changes. The adenomatous polyposis coli (APC), one of the tumor suppressor genes, has a gatekeeper function in the colonic mucosa [37]. Mutations to the APC tumor suppressor gene constitute an important initiating factor in the early stages of the adenoma-carcinoma sequence. Secondly, tobacco smoking is related to colorectal carcinogenesis, which is affected by the carcinogens formed during the burning of tobacco, including polynuclear aromatic hydrocarbons, nitrosamines, and aromatic amines [38]. Nicotine and its metabolite, 4-(methylnitrosamino)-1-(3-pyridyl)-1-butanone (NNK), are the most characteristic components of tobacco for smoking-related malignancies. Nicotine and NNK have been shown to induce CRC growth and even to enhance the migration of cancer cells [37]. These mechanisms could be applied to the formation of a CRA due to exposure to ETS. Although the concentrations of carcinogens from exposure to ETS are relatively low when compared with those from active smoking, prolonged exposure may lead to a considerable accumulation of carcinogens. Additionally, we should not overlook the role of exposure to ETS because several carcinogens are present at higher levels in side-stream stroke than in main-stream smoke [39].

The current study has several limitations. Firstly, we were unable to do analyses based on different measures of exposure to passive smoking. We did not have sufficient information on the duration of exposure, the types of cigarettes smoked, and the places of exposure. Moreover, the result of this study may be due to exposure misclassification because individual exposure to ETS is influenced by many factors, such as space volume, ventilation, and actual time spent in tobacco smoke, that are difficult to measure accurately. Secondly, the use of self-reported questionnaires rather than personal interviews may have affected the reliability of the data. However, random re-evaluation of questionnaire responses by physicians at later consultation sessions alleviated the error in the data collection processes. Thirdly, lack of information on other confounding variables (dietary intake of fruits, vegetables, and meats) related to the risk for developing a CRA was another limitation in this study. Lastly, this study was conducted at one center, and the study population consisted of only ethnic Asians, which may have caused selection bias. Therefore, future studies will be necessary to determine whether the results of this study can be replicated in other racial populations. Despite these limitations, our study had the strength of being one of the first studies to investigate the relationship between exposure to ETS in the workplace and the risk for developing a CRA. Additionally, we confined the study subjects to those with a first-time diagnosis of a CRA. Thus, our study did not include those who previously had had a CRA removed and had undergone a procedure such as a polypectomy and/or cold biopsy and/or endoscopic submucosal dissection. Additionally, we accounted for other potential confounding factors that might affect the risk for developing a CRA (e.g., use of NSAIDs and aspirin, HRT for females, and vitamin D intake).

In conclusion, occupational exposure to ETS was found to be associated with an increased risk for developing a CRA, especially in former smokers. Thus, a more intensive surveillance of colorectal adenomatous polyps and neoplasms, for example, by using colonoscopy or barium study of the large intestine, should be emphasized in this population of individuals. Additionally, our investigation supports the benefits of smoke-free laws to diminish exposure to ETS in the workplace. For clarification of the causal relationship between exposure to ETS in the workplace and the risk for developing a CRA, further large-sample-size retrospective studies that consider the intensity and the duration of exposure to ETS in the workplace, as well as the effect of exposure to ETS at locations other than workplace, are required.

\section{CONFLICT OF INTEREST}

No potential conflict of interest relevant to this article was reported.

\section{REFERENCES}

1. Zorzi M, Fedeli U, Schievano E, Bovo E, Guzzinati S, Baracco S, et al. Impact on colorectal cancer mortality of screening programmes based on the faecal immunochemical test. Gut 2015;64:784-90.

2. Heitman SJ, Hilsden RJ, Au F, Dowden S, Manns BJ. Colorectal cancer screening for average-risk North Americans: an economic evaluation. PLoS Med 2010;7:e1000370.

3. Hamilton W, Lancashire R, Sharp D, Peters TJ, Cheng K, Marshall T. The risk of colorectal cancer with symptoms at different ages and between the sexes: a case-control study. BMC Med 2009;7:17.

4. Kim KM, Lee SH, Lee DJ, Kim KN, Seo SW, Lee HS, et al. A randomized controlled trial of comparison on time and rate of cecal and termianl Ileal intubation according to adult-colonoscope length: intermediate versus long. J Korean Med Sci 2014;29:98-105.

5. Kim DH. Colorectal cancer epidemic in Korea. Ann Coloproctol 2013;29:1-4.

6. Foda AA, El-Hawary AK, Abdel-Aziz A. Matrix metalloproteinase-13 expression in the progression of colorectal adenoma to carcinoma: matrix metalloproteinase- 13 expression in the colorectal adenoma and carcinoma. Tumour Biol 2014;35:5653-8.

7. Kim YJ, Lee KJ, Park SY, Han JH, Kwon KY, Kim JH. Association between dyslipidemia and the prevalence of colon polyps based on a health evaluation of subjects at a hospital. Korean J Fam Med 2014;35:143-51.

8. Sohn DK; Colonoscopy Study Group of the Korean Society of Coloproctology. A survey of colonoscopic surveillance after polypectomy. Ann Coloproctol 2014;30:88-92.

9. Lieberman DA, Weiss DG, Bond JH, Ahnen DJ, Garewal H, Chejfec G. Use of colonoscopy to screen asymptomatic adults for 
colorectal cancer. Veterans Affairs Cooperative Study Group 380. N Engl J Med 2000;343:162-8.

10. Winawer SJ, Zauber AG, Ho MN, O'Brien MJ, Gottlieb LS, Sternberg SS, et al. Prevention of colorectal cancer by colonoscopic polypectomy. The National Polyp Study Workgroup. N Engl J Med 1993;329:1977-81.

11. Florescu A, Ferrence R, Einarson T, Selby P, Soldin O, Koren G. Methods for quantification of exposure to cigarette smoking and environmental tobacco smoke: focus on developmental toxicology. Ther Drug Monit 2009;31:14-30.

12. Jaakkola MS, Jaakkola JJ. Assessment of exposure to environmental tobacco smoke. Eur Respir J 1997;10:2384-97.

13. Ahmed FE. Effect of diet, life style, and other environmental/chemopreventive factors on colorectal cancer development, and assessment of the risks. J Environ Sci Health C Environ Carcinog Ecotoxicol Rev 2004;22:91-147.

14. Paskett ED, Reeves KW, Rohan TE, Allison MA, Williams CD, Messina CR, et al. Association between cigarette smoking and colorectal cancer in the Women's Health Initiative. J Natl Cancer Inst 2007;99:1729-35.

15. Fu Z, Shrubsole MJ, Smalley WE, Ness RM, Zheng W. Associations between dietary fiber and colorectal polyp risk differ by polyp type and smoking status. J Nutr 2014;144:592-8.

16. Stegeman I, de Wijkerslooth TR, Stoop EM, van Leerdam ME, Dekker E, van Ballegooijen M, et al. Colorectal cancer risk factors in the detection of advanced adenoma and colorectal cancer. Cancer Epidemiol 2013;37:278-83.

17. Fu Z, Shrubsole MJ, Li G, Smalley WE, Hein DW, Cai Q, et al. Interaction of cigarette smoking and carcinogen-metabolizing polymorphisms in the risk of colorectal polyps. Carcinogenesis 2013; 34:779-86.

18. Reid ME, Marshall JR, Roe D, Lebowitz M, Alberts D, Battacharyya $\mathrm{AK}$, et al. Smoking exposure as a risk factor for prevalent and recurrent colorectal adenomas. Cancer Epidemiol Biomarkers Prev 2003;12:1006-11.

19. Verla-Tebit E, Lilla C, Hoffmeister M, Brenner H, Chang-Claude J. Exposure to environmental tobacco smoke and the risk of colorectal cancer in a case-control study from Germany. Eur J Cancer Prev 2009;18:9-12.

20. Peppone LJ, Reid ME, Moysich KB, Morrow GR, Jean-Pierre P, Mohile SG, et al. The effect of secondhand smoke exposure on the association between active cigarette smoking and colorectal cancer. Cancer Causes Control 2010;21:1247-55.

21. Greenfield TK. Ways of measuring drinking patterns and the difference they make: experience with graduated frequencies. J Subst Abuse 2000;12:33-49.

22. Goh VH, Hart WG. Associations of physical exercise as a lifestyle habit with lean and fat body mass and handgrip strength and age in Asian men. Aging Male 2014;17:131-5.

23. Kim KH, Lee CM, Park SM, Cho B, Chang Y, Park SG, et al. Secondhand smoke exposure and osteoporosis in never-smoking postmenopausal women: the Fourth Korea National Health and
Nutrition Examination Survey. Osteoporos Int 2013;24:523-32.

24. Manuel J. Double exposure. Environmental tobacco smoke. Environ Health Perspect 1999;107:A196-201.

25. Merletti F, Richiardi L, Boffetta P. Health effects of passive smoking. Med Lav 1998;89:149-63.

26. Muggli ME, Hurt RD, Repace J. The tobacco industry's political efforts to derail the EPA report on ETS. Am J Prev Med 2004;26: 167-77.

27. Gerhardsson de Verdier M, Plato N, Steineck G, Peters JM. Occupational exposures and cancer of the colon and rectum. Am J Ind Med 1992;22:291-303.

28. Slattery ML, Edwards S, Curtin K, Schaffer D, Neuhausen S. Associations between smoking, passive smoking, GSTM-1, NAT2, and rectal cancer. Cancer Epidemiol Biomarkers Prev 2003;12:882-9.

29. Nishino Y, Tsubono Y, Tsuji I, Komatsu S, Kanemura S, Nakatsu$\mathrm{ka} \mathrm{H}$, et al. Passive smoking at home and cancer risk: a population-based prospective study in Japanese nonsmoking women. Cancer Causes Control 2001;12:797-802.

30. Hassan MM, Abbruzzese JL, Bondy ML, Wolff RA, Vauthey JN, Pisters PW, et al. Passive smoking and the use of noncigarette tobacco products in association with risk for pancreatic cancer: a case-control study. Cancer 2007;109:2547-56.

31. Vineis P, Airoldi L, Veglia F, Olgiati L, Pastorelli R, Autrup H, et al. Environmental tobacco smoke and risk of respiratory cancer and chronic obstructive pulmonary disease in former smokers and never smokers in the EPIC prospective study. BMJ 2005;330:277.

32. Reynolds P, von Behren J, Fontham ET, Correa P, Wu A, Buffler $\mathrm{PA}$, et al. Occupational exposure to environmental tobacco smoke. JAMA 1996;275:441-2.

33. Johnson KC, Miller AB, Collishaw NE, Palmer JR, Hammond SK, Salmon AG, et al. Active smoking and secondhand smoke increase breast cancer risk: the report of the Canadian Expert Panel on Tobacco Smoke and Breast Cancer Risk (2009). Tob Control 2011;20:e2.

34. Barnoya J, Glantz SA. Cardiovascular effects of secondhand smoke: nearly as large as smoking. Circulation 2005;111:2684-98.

35. McCarville M, Sohn MW, Oh E, Weiss K, Gupta R. Environmental tobacco smoke and asthma exacerbations and severity: the difference between measured and reported exposure. Arch Dis Child 2013;98:510-4.

36. Tan CE, Glantz SA. Association between smoke-free legislation and hospitalizations for cardiac, cerebrovascular, and respiratory diseases: a meta-analysis. Circulation 2012;126:2177-83.

37. Wei PL, Lin SY, Chang YJ. Cigarette smoking and colorectal cancer: from epidemiology to bench. J Exp Clin Med 2011;3:257-61.

38. Giovannucci E, Martínez ME. Tobacco, colorectal cancer, and adenomas: a review of the evidence. J Natl Cancer Inst 1996;88:1717-30.

39. IARC monographs on the evaluation of carcinogenic risks to humans. Diesel and gasoline engine exhausts and some nitroarenes. International Agency for Research on Cancer. IARC Monogr Eval Carcinog Risks Hum 1989;46:1-458. 